POLIIICAL ECONOM Y RESEARCH INSTIIUTIE


Robert Pollin

Andong Zhu

October 2005

Gordon Hall

418 N Plea sant St., Suite A

Amherst, MA 01002

Telephone: (413) 545-6355 Facsimile: (413) 545-2921

E-mail: peri@eco ns.umass.edu Website:

http://www.umass.edu/ peri/

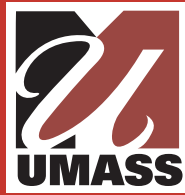




\title{
Inflation and Economic Growth: A Cross-Country Non-linear Analysis
}

\author{
By Robert Pollin \\ Department of Economics and Political Economy Research Institute (PERI) \\ University of Massachusetts-Amherst \\ pollin@econs.umass.edu \\ and \\ Andong Zhu \\ The Marxism Research Institute \\ Tsinghua University, Beijing, China \\ adzhu_1999@yahoo.com
}

October 2005

This paper was written as part of a broader project on pro-poor macroeconomic policies in Sub-Saharan Africa, under the sponsorship of the United Nations Development Program. We are most grateful for the support of the UNDP. We are also grateful for comments on this specific aspect of the broader project from our co-workers Jerry Epstein, James Heintz, Leonce Ndikumana as well as from Michael Ash. 


\title{
Inflation and Economic Growth: A Cross-Country Non-linear Analysis
}

\section{By Robert Pollin and Andong Zhu October 2005}

Keywords: Inflation, economic growth, regression analysis, monetary policy JEL codes: E31, E52

\begin{abstract}
This paper presents new non-linear regression estimates of the relationship between inflation and economic growth for 80 countries over the period $1961-2000$. We perform tests using the full sample of countries as well as sub-samples consisting of OECD countries, middle-income countries, and low-income countries. We also consider the full sample of countries within the four separate decades between $1961-2000$. Considering our full data set we consistently find that higher inflation is associated with moderate gains in GDP growth up to a roughly 15 - 18 percent inflation threshold. However, the findings diverge when we divide our full data set according to income levels. With the OECD countries, no clear pattern emerges at all with either the inflation coefficient or our estimated turning point. With the middle income countries, we return to a consistently positive pattern of inflation coefficients, though none are statistically significant. The turning points range within a narrow band in this sample, between $14-$ 16 percent. With the low income countries, we obtain positive and higher coefficient values on the inflation coefficient than with the middle-income countries. With the groupings by decade, the results indicate that inflation and growth will be more highly correlated to the degree that macroeconomic policy is focused on demand management as a stimulus to growth. We consider the implications of these findings for the conduct of monetary policy. One is that there is no justification for inflation-targeting policies as they are currently being practiced throughout the middle- and low-income countries, that is, to maintain inflation with a $3-5$ percent band.
\end{abstract}




\section{Introduction}

This paper presents new cross-country evidence between 1961 - 2000 on the relationship between inflation and economic growth. Despite the central importance of this inflation-growth relationship for macroeconomic theory and policy, there is nothing close to a professional consensus as to what the empirical evidence tells us about this relationship.

The results we present here have direct relevance to the debate on inflation targeting as an appropriate framework for conducting monetary policy. Over the past decade, governments throughout the world have embraced inflation targeting as a dominant policy framework. For the most part, this specifically means that they have set a low band of acceptable inflation rates as a primary target in the conduct of economic policy. This band is usually between a $3-5$ percent annual inflation rate. They have then maintained sufficiently high short-term interest rates as the intermediate policy instrument for preventing inflation from exceeding that target band. Higher interest rates are aimed, in turn, at reducing economic growth. Slower economic growth should then dampen inflationary pressures. At least in the short-run, the costs in terms of slower growth of containing inflation within this $3-5$ percent band are evident. But proponents of inflation targeting hold that, over a longer-term framework, maintaining low inflation will itself yield benefits for growth that exceed these short-term costs. ${ }^{1}$

Some limitations of inflation targeting have been widely recognized by mainstream economists and even U.S. central bankers Ben Bernanke and Alan Blinder (see Bernanke, Laubach, Posen and Mishkin 1999; and Blinder 1998). The Bernanke/Blinder view is that inflation targeting does not provide an approach to maintaining low inflation that is clearly superior to other approaches. This is true as such, but this concern about inflation targeting as an operating procedure alone begs a more important question. This crucial question is whether maintaining inflation within a band of $3-5$ percent itself is, as a generalization, supportive of economic growth, regardless of the technique being used to maintain inflation within that low band. It is this broader question that we address in this paper. That is, are countries making sacrifices in terms of their economic growth path by focusing macroeconomic policy on maintaining inflation at no more than $3-5$ percent?

In Section 2, we briefly review the overarching and longstanding analytic debates on the relationship between inflation and economic growth, then focus specifically on the recent econometric research that has explored that relationship. In Section 3, we present basic descriptive data from our data sample, then examine the main results from our various economic exercises. In the concluding Section 4, we consider the broader implications of our findings, especially as they relate to policy debates around inflation targeting and possible alternative approaches to inflation control.

\footnotetext{
${ }^{1}$ An excellent survey of inflation-targeting and related issues in global monetary macroeconomics is Saad Filho (2005)
} 


\section{Literature Overview}

\section{Analytic perspectives}

We begin by separating out the phenomenon of hyperinflation, which we broadly define as being annual inflation rates in excess of 40 percent per year. Hyperinflations occur through a variety of specific factors. But regardless of their specific origins, hyperinflations represent a breakdown of economic functionings. We will assume that hyperinflations correspond with, and are detrimental to, a positive economic growth path. We are therefore leaving aside here the possibility that there may be some positive correspondence between inflation above 40 percent and economic growth.

Hyperinflations aside, the relationship between inflation and growth has been at the very center of macroeconomic theory debates since the monetarist counterrevolution against Keynesianism beginning in the 1960s. ${ }^{2}$ The main progeny of that counterrevolution - the "natural rate of unemployment," the vertical Phillips Curve, and New Classical Economics more generally-have been focused largely around demonstrating that there can be no positive benefits for economic growth or employment of operating an economy at anything above a minimal inflation rate in the range of $2-3$ percent. From this perspective, inflation impedes efficient resource allocation by obscuring the signaling role of relative price changes, which, in turn, is the most important guide to efficient economic decision-making.

This position contrasts sharply with the Keynesian perspective and the early Phillips Curve models, which held that inflation and economic growth can be positively associated when inflationary pressures emerge as a byproduct of rising aggregate demand. In this Keynesian framework, it is not the case that inflation is itself a positive engine of growth, certainly not a primary growth-inducing force. The point is rather that, if rising aggregate demand is leading to increased growth, then some inflationary pressures are likely to emerge in this scenario as a relatively benign byproduct. Within this Keynesian framework, there could also be reasons for inflation and growth to be negatively correlated. This would occur when inflation results from monopolistic pricing practices, exchange rate volatility or supply shocks. These problems can also be compounded when adequate policy interventions do not occur to dampen the inflationary impulses induced by monopolistic pricing, exchange rate volatility or supply shocks.

\section{Recent Empirical Studies}

Probably the most influential recent contribution to the econometric literature on inflation and growth is that of Bruno and Easterly (with results presented in both Bruno 1995 and Bruno and Easterly 1998). Bruno and Easterly examined the relationship between inflation and economic growth for 127 countries between 1960 and 1992. Their examination of this data set is historical and descriptive. They do not present a formal econometric model.

\footnotetext{
2 The literature on this issue is of course vast. Three references offering different perspectives are Cross (1995) Krueger and Solow (2001) and Saad Filho (2005).
} 
Their key conclusion was that there is no robust evidence from this data sample demonstrating a trade-off between output growth and inflation. More specifically, only on the basis of two conditions could one observe a negative growth-inflation relationship at all in their data sample. These were: 1) the inclusion in the data sample of very high inflation experiences, i.e. rates of inflation of 40 percent and higher; and 2) increasing the frequency of the data observations. As they write, "The results get stronger as one goes from the cross-section to ten year averages to five year averages to annual data,” (1998, p. 4).

Once one controls for these two factors, Bruno and Easterly found that average growth rates fell only slightly as inflation rates moved up to $20-25$ percent. For inflation rates below 20 percent, Bruno concluded that "there is no obvious empirical evidence for significant long-run growth costs,” (Bruno 1995, p. 38). Moreover, of particular importance for our concerns with aggregate demand effects on inflation and growth, Bruno found that during 1960 - 72, economic growth on average increased as inflation rose, from negative or low rates to the $15-20$ percent range. This is because, as Bruno explained, "in the 1950s and 1960s, low-to-moderate inflation went hand in hand with very rapid growth because of investment demand pressures in an expanding economy,” (1995, p. 35). Thus, inflation that results directly from economic expansion does not, according to Bruno’s findings, create any significant barriers to expansion.

Despite these findings, Bruno still makes clear in his single-authored paper that he does not advocate complacency with respect to inflation rates in the 20 percent region. According to Bruno, once inflation moves into the 20 percent region, it is difficult to contain at this level. This is because, within the 20 percent inflation region, the systems of indexing wages and financial assets, as well as exchange rate adjustments, become more frequent. This then creates a momentum toward accelerating inflation.

Neither Bruno alone nor Bruno and Easterly provide systematic evidence in behalf of Bruno's concerns about inflation within the 20 percent region. Nevertheless, Bruno is clear in his conclusion that "getting inflation down to single digits is important even for longer-term growth reasons,” (p. 38). But even within this less systematic discussion on the dangers of inflation in the 20 percent range, it is still notable that Bruno never suggests that inflation needs to be pushed below a single-digit threshold —and specifically down into the $3-5$ percent range advocated by proponents of inflation targeting.

Since the Bruno and Easterly study, various researchers have examined the output growth-inflation relationship through more formal techniques than those employed by Bruno and Easterly while still searching out, as with Bruno and Easterly, potential nonlinearities. For example, in a 1998 paper, IMF economists Atish Ghosh and Steven Phillips combine panel regression techniques with non-linear treatment of the inflationgrowth relationship. They also utilize a decision-tree technique that, in their view, is more robust to outliers and non-linearities than is standard regression analysis. Their model draws from a data sample of IMF member countries over 1960 - 96. According to this model, they find evidence of a negative inflation threshold at $2 \frac{1}{2} 2$ percent. But 
they also acknowledge that thresholds of 5 or 10 percent generate statistical results very similar to the $2 \frac{1}{2}$ percent threshold.

A 2001 paper by two separate IMF economists Moshin Khan and Abdelhak Senhadji offers two innovations relative to Ghosh and Phillips. The first is their use of conditional least squares, a new non-linear estimation technique,. The second, and more straightforward innovation was to divide their data sample into industrial and developing countries. Based on this approach, they find that the threshold level above which inflation significantly slows growth is $1-3$ percent for industrial countries and $11-12$ percent for developing countries.

More recently still, a 2004 paper by Burdekin, Denzau, Kiel, Sitthiyot, and Willett followed Khan and Senhadji in allowing for different threshold effects among the industrial and developing countries. They also allow for non-linearities in the growthinflation relationship through utilizing spline estimation techniques. The results from this research diverge sharply from Khan and Senhadji. In terms of point estimates, they found that the turning point for industrial countries was eight percent while that for developing countries was three percent.

In short, all of these studies are in broad concurrence with Bruno and Easterly as to the presence of non-linearities in the growth-inflation relationship. They also broadly concur with Bruno's conclusion that the negative effects of inflation will occur somewhere below a 20 percent threshold, most likely in the single-digit range. However, they diverge sharply as to where the turning point occurs within a range of roughly 12 percent inflation or less. Moreover, the two studies that adopted the simple innovation of dividing the sample between industrial and developing countries reached opposite conclusions as to which set of countries had a higher inflation threshold. Thus, despite the deployment of sophisticated techniques for capturing the impact of non-linearities in the growth-inflation relationship, major questions remain unresolved. In particular, there remains no robust evidence in support of a policy goal of maintaining an inflation target in the range of $3-5$ percent.

\section{Descriptive Data and Econometric Evidence}

Our own model is a straightforward panel data model, in which we aim to isolate the effects of inflation on economic growth through including a series of control variables as well as allowing for a non-linear component to the growth-inflation relationship. Our data sample runs from 1961 - 2000, including data from a total of 80 countries. We have excluded from the model countries whose population is less than 2 million people. We do this to focus our empirical exercises on countries whose economies are minimally large enough so that the countries' patterns of economic activity can be understood as having features that are distinct to that country. The appendix to the paper provides a full list of the countries in our data sample.

\section{Descriptive statistics}


We first provide some basic descriptive statistics from our data sample, provided both in Table 1 and Figure 1. Table 1 shows both means and standard deviations for inflation and growth, for the full sample, and broken out according to our three incomelevel groupings. For all countries in the sample, as we see, the average rate of GDP growth is 1.9 percent and the average inflation rate is 10.2 percent. However, from the standard deviations - 2.7 percent for GDP growth and 7.2 percent for inflation-we also see that there are wide disparities among the observations in the sample.

\section{TABLE 1 BELONGS HERE}

The disparities do diminish as we break out the full sample of countries into income-level groupings. Not surprisingly, the OECD countries experience the highest average rate of economic growth (virtually by definition; see footnote \#3) and the lowest average inflation rates. Average growth is significantly faster in the middle-income countries relative to the low-income countries, but average inflation is somewhat lower in the low-income countries.

The four scatter plots in Figure 1 show the range of values for our data sample more fully. No strong patterns at all emerge from these figures in terms of the inflation/GDP growth relationship. Of course, these data plots do not control for factors other than inflation that could be affecting economic growth.

\section{FIGURE 1 BELONGS HERE}

We label in the four diagrams the data points that emerge as outliers through simple observation. This provides some useful perspective. For example, with the full set of countries, the most rapid growth spurt was experienced by Haiti from 1996 - 2000 . Haiti grew on average by 15.2 percent in this period, even while inflation was rising at an average of 14.9 percent. In terms of other outliers in the all-country diagram, we see that the very high inflation and/or very low growth outliers are all low- or middle-income countries, with Rwanda, Nicaragua, and Zimbabwe all experiencing severe political conflicts during their low growth/high inflation years.

With the OECD and middle-income country diagrams, we see that the countries able to experience the most rapid economic growth rates were Japan, Ireland, South Korea, and China. In all cases, the rapid GDP growth was tied to reaching new levels of export success. Inflation in these countries over the relevant years ranged widely, between 2.6 and 13.2 percent. Clearly, it is difficult to offer generalizations from these figures as to the interrelationship between inflation and economic growth. It is evident that we need to examine this relationship more systematically, the task to which we now turn.

\section{Econometric model}


Our approach has been to build a formal model that is still consistent with the main strength of the Bruno-Easterly framework, which is its simplicity. To do this, we work with a panel model that incorporates non-linearities through two relatively simple procedures.

The first feature of our non-linear model is to simply exclude from our data set all observations in which inflation exceeded 40 percent. As we mention above, we accept the finding of Bruno and Easterly that inflation in that high range will produce negative effects on growth. We are therefore effectively asking with our model whether an annual inflation rate below 40 percent exerts a negative effect on economic growth, and if so, at what point are such negative effects likely to emerge?

The second way that we introduce non-linearity in our model is to include the squared term on inflation as an explanatory variable, which means we are estimating the regression equations as a second-degree polynomial. This is a straightforward, widely used technique for estimating non-linear relationships, through allowing for changes in slopes as a function of changes in the independent variable. In this case, the slope of the estimating equation can vary with changes in the inflation rate. This enables us to observe turning points in the relationship between inflation-growth and inflation-equality. We can observe such possible turning points through this calculation:

Turning point $=-(($ inflation coefficient $) /(2 *($ inflation-squared coefficient $))$.

Within this framework, we then also pursue robustness tests through three sets of straightforward procedures:

A) We utilize four different panel data techniques: pooled OLS, between effects, fixed effects, and random effects. In principle, researchers are supposed to establish through diagnostic exercises which of the four techniques is appropriate with a given data sample. In practice, however, it is frequently difficult to know which technique is the most reliable. Each of the techniques has both strengths and weaknesses. A pooled OLS model implicitly assumes there are no problems of omitted variables in a model, which is not likely to be true, even through frequently the problems may not be serious enough to substantially distort one's results. A between-effects model averages the data for each country into one observation. It is therefore testing more narrowly for variation on a country-by-country basis, as opposed to considering variation between time periods as well as countries. With the fixed effects model, we are allowing for intercept shifts to occur for each country, based on the range of possible omitted variables in evaluating country-by-country determinants of economic growth. But the fixed effects model effectively creates dummy variables for each country in the sample, which reduces degrees of freedom. Finally, the random effects model also allows for a different intercept for each country in the sample. But the random effects model isolates these individual country effects in the error term, and therefore does not reduce degrees of freedom in the manner of the fixed effects estimator. But at the same time, to be an unbiased estimator, the random effects model requires that the omitted variable effects will be uncorrelated with the explanatory variables. 
Given this range of concerns with the various techniques, we report results utilizing all four techniques. By examining results generated by all four techniques, we are able to assess the robustness of our findings across the range of panel data estimators.

B) We run regressions both on the full set of countries as one sample, then through dividing the countries into three groupings, OECD countries, middle-income countries, and low-income countries. We are therefore able to observe the extent to which differences in the results are due to broad differences in the various countries' level of development, as distinct from the individual country differences that we control for through the fixed- and random-effects models. ${ }^{3}$

C) We decompose the full time period into four decade-long sub-periods. This enables us to examine how the relationships may have changed over time. We are especially interested in following up on Bruno's observation that inflation and growth were positively correlated during from the 1960s up until the 1973 oil shock. This was a period in which, as Bruno said, inflation emerged out of explicit efforts to stimulate aggregate demand.

Beyond these distinct features of our model, we also incorporate a set of control variables in each specification of the model. These control variables are standard in cross-country estimates of the determinants of economic growth. They include 1) the initial level of GDP; 2) the share of investment spending in GDP; 3) the share of government spending in GDP; 4) the fiscal deficit; 5) educational levels; 6) the level of overall health, as measured by life expectancy; 7) the change in terms of trade; 8) the effects of natural disasters; and 9) the effects of wars. In addition, we include dummy variables for each year in the pooled-OLS, fixed effects, and random effects models to control for the time effects within each set of country observations. Full descriptions of each of the control variables is reported in the appendix. We do not report here the full set of results on the control variables, but these results are available on request. ${ }^{4}$

We report the key findings of our econometric models in Tables 2 and 3. Both tables report the coefficients and t-statistics for the inflation and inflation-squared

\footnotetext{
${ }^{3}$ Grouping the countries in the sample by average GDP levels does raise the potential for significant bias in the regression. This is because the dependent variable in the model is GDP growth. Strictly speaking, we are not dividing the sample based on the dependent variable, but there is obviously a close correspondence between the growth of GDP, our dependent variable, and GDP levels, the variable on which we truncate the sample. To test for bias here, we have also divided the full sample based on pre-1960 GDP level groupings - that is, on the basis of data points that precede in time our sampling period. In this case, the division is between current OECD countries and the non-OECD countries - that is, the demarcation between middle- and low-income countries was not so evident in the pre-1960 data, and only becomes evident over the forty years that constitute our data sample. However, the results of this exercise do not vary substantially from those reported with the three GDP-level groupings reported here. This suggests that any potential bias from the GDP-level groupings is not a serious problem for our substantive understanding of the findings.

${ }^{4}$ By exploring the inflation-growth relationship within this framework of a standard cross-country growth regression model, we are building in an assumption that causality in the relationship is running from inflation to growth. We do not explore the issue of simultaneity or reverse causality in this exercise, while we recognize it as an important issue for further research.
} 
variables only for each of the regressions. We also report the turning points estimated by each equation when inflation switches from becoming a positive to negative, or negative to positive, influence on growth.

Results for the Full Time Period. The results for the full time period are presented in Table 2. Considering first the data for all countries in the sample, we see that the sign of the inflation coefficient is consistently positive across specifications, and is statistically significant in all but the fixed effects specification. Moveover, the coefficient values across specifications are similar, ranging between $0.09-0.15$. The coefficients on the inflation-squared terms are also similar and statistically significant in all cases. With the coefficients on the inflation and inflation-squared terms, we can then calculate the turning points as being between a 15.2 and 18.6 inflation rate. Overall, this first set of tests with the full data sample suggest that the rate of economic growth rises by between about 0.1 and 0.15 percent for every percentage point increase in the inflation rate up to a $15-18$ percent threshold. Inflation then becomes a damper on growth beyond this threshold.

\section{TABLE 2 BELONGS HERE}

The clear findings we obtain with the full data set is, however, not maintained when we consider OECD, middle-income, and low-income countries separately. With the data grouped by income levels, we expect that the significance levels will go down due to the smaller sample sizes. And we do indeed observe generally lower significance levels with the results grouped by income levels.

More specifically, in the case of the OECD countries, none of the coefficients for inflation or inflation-squared are statistically significant in any of the specifications. Moreover, the signs on the inflation variable shift to negative in the pooled OLS, between effects and random effects models. In short, we do not obtain any reliable results on the inflation-growth relationship for the OECD countries.

With the middle-income countries, the signs on the inflation coefficient are all positive. However, the coefficients are insignificant in all cases, the coefficient values correspondingly jump from 0.06 to 0.129 . However, the estimated turning points in these equations are within a tight band of between $14-16$ percent.

Finally, with the low-income countries, we do again obtain consistently positive coefficient values from the inflation variable. These coefficients are also significant in the fixed effects and random effects models. The coefficient values in these regressions are substantially higher than with the other country groupings, ranging between 0.24 and 0.56 . The inflation-squared terms are also strongly significant in the fixed- and randomeffects models. The turning point estimates range between 15 - 23 percent.

Results by Decade. In Table 3, we report results from regressions run separately for each of the four decades in our data sample. These regressions are run with annual data rather than five-year averages in order to generate a larger number of observations. 
In doing this, we recognize the point emphasized by Bruno and Easterly, that we should expect more of a negative correspondence between inflation and growth as we move to higher-frequency data samples. This is because of the likelihood that negative effects on growth will occur through short bursts of high inflation rates that approach our cut-off figure of 40 percent. Such short bursts of high inflation and slow or negative growth will be smoothed out when data are grouped at lower frequencies.

\section{TABLE 3 BELONGS HERE}

One key point emerges from the results in Table 3: that the evidence for a positive association between growth and inflation is far stronger in the 1961 - 70 decade than in subsequent decades. For 1961 - 70, the coefficient values on inflation are all positive, though statistically significant only in the between-effects model. The fixed effects model stands apart with a low inflation coefficient value of 0.065 , but otherwise the coefficients for the other specifications are high, at 0.11 for the pooled OLS and random effects models and a very high 0.61 for the between effects model.

With the 1971 - 80 sample, the inflation coefficients remain positive, but the coefficient values and levels of significance fall off, especially with the random effects and between effects models. For 1981 - 90, the inflation coefficients all turn negative, and is a statistically significant negative value in the fixed effects model. Finally, for 1991 - 2000, we obtain negative inflation coefficients with two tests and close to zero coefficients for the other two.

These results provide broad support for Bruno's observation cited above, about inflation and growth moving positively together during the 1960s in correspondence with, as he put it, "very rapid growth because of investment demand pressures in an expanding

economy," (1995, p. 35). During the 1970s, demand-management policies were still in favor to support growth. But the positive associations between growth and inflation as a byproduct of growth in this period were undermined by the two oil price shocks in 1973 and 1979. The overall inflation experience of this decade therefore is a combination of demand-pull effects from growth and supply-side shocks. It is therefore not surprising that the inflation coefficients in the 1970s fall in value and lose significance.

The 1980s marked the beginning of what Angus Maddison (2001), among others, has term the "neoliberal era." Probably the single defining feature of this era is the virtual abandonment by governments throughout the world of Keynesian demand management policies as a tool for stimulating growth and employment. Thus, as a broad generalization, the inflation that is experienced in the 1980s and 1990s emerges almost entirely as a result of supply shocks and inertia, as opposed to demand-pull pressures. Within this context, it is also not surprising that the inflation coefficients become consistently negative, albeit generally not to a statistically significant extent.

\section{Conclusions}


Considering first our full data set of 80 countries between 1961 - 2000, we have consistently found that higher inflation is associated with moderate gains in GDP growth up to a roughly 15 - 18 percent inflation threshold.

However, the findings diverge when we divide our full data set according to income levels. With the OECD countries, no clear pattern emerges at all with either the inflation coefficient or our estimated turning point. Both the signs on the inflation coefficients as well as the turning points are highly sensitive to specifications. With the middle income countries, by contrast, we return to a consistently positive pattern of inflation coefficients, though none are statistically significant. However, the turning points range within a narrow band in this sample, between 14.0 and 16.3 percent. With the low income countries, we obtain positive and higher coefficient values on the inflation coefficient than with the middle-income countries. These coefficients are also statistically significant with the fixed- and random-effects models.

Finally, with the groupings by decade, the results broadly indicate that inflation and growth will be more highly correlated to the degree that macroeconomic policy is focused on demand management as a stimulus to growth as opposed to macroeconomic austerity and inflation targeting.

Overall, there is no evidence from this research supportive of a policy of maintaining inflation within a low band of about $3-5$ percent, to the degree that government policymakers are interested in promoting economic growth and employment, rather than merely low inflation as an end in itself. At the same time, there is also no evidence that governments should allow inflation to rise above a 15 - 20 percent range in an effort to spur growth.

This suggests that there is still a wide range of inflation rates that are very likely to be associated positively with economic growth. Certainly for the middle- and lowincome countries, our results strongly suggest that allowing inflation to be maintained in range of 10 percent or somewhat higher is very likely to be consistent with higher rates of economic growth. This is most especially the case when inflation is resulting from, as Bruno put it, "investment demand pressures in an expanding economy."

For the OECD countries, the primary conclusion that we can reach from our results is a negative one: that no generalization about the inflation-growth relationship is likely to find robust support from the available evidence. What appears likely for the OECD countries is that the wide range of relationships that emerge from the data reflect the differences in the sources of inflation - that is, whether inflation has resulted primarily from Keynesian type demand-pull forces as opposed to supply shocks and inertia.

Some broad policy implications flow from these results. The first is that there is no justification for inflation-targeting policies as they are currently being practiced throughout the world, that is, to maintain inflation with a $3-5$ percent band and to adjust short-term interest rates as needed to dampen inflationary pressures beyond that targeted 
band. As a corollary, there is very likely to be positive growth benefits in middle- and low-income countries from allowing inflation to rise to a high-single digit range or even in some cases up to about 15 percent rather than dampening inflationary pressures through raising short-term interest rates. This is especially true to the extent that inflation within this range is resulting from demand-pull forces as opposed to supply shocks and inertia. ${ }^{5}$

A second implication is that researchers are likely to make productive contributions through giving increased attention on the inflation-growth relationship to some relatively under-explored aspects of the issue. The first is to be able to sort out with increased specificity the sources of inflationary pressures, given the likely wide disparities in the inflation-growth relationship depending on what is fueling inflation. A second is to focus more on policy measures for dampening inflation not at very low levels, but rather at levels approaching the upper limit of the positive growth-inflation association. This would be in the range of 10 - 15 percent for middle- and low-income countries. With the OECD countries, the acceptable range is likely to depend entirely on what are the primary sources of inflationary pressures.

One well-known policy tool for maintaining inflationary pressures within a positive threshold range is some variation of incomes policies. Incomes policies have been widely used as an inflation control tool in a variety of contexts. One common situation has been in bringing down inflation after it has risen to a range above 40 percent. For example, in their paper "Moderate Inflation,” (1991) Dornbusch and Fischer describe how Mexico in the 1980s drew upon experiences in Argentina, Brazil, Peru, and Israel in developing a strategy to bring inflation down from the 100 percent range to something closer to 20 percent. Dornbusch and Fischer reported that the Mexicans learned two lessons from these experiences, 1) "that disinflation without fiscal discipline was unsustainable;" but that 2) “disinflation without incomes policy, relying solely on tight money and tight budgets, would be unnecessarily expensive,” (p. 31). In analyzing the Israeli experience with disinflation over the 1980s, Bruno documents in detail the major contributions of incomes policies to the success of the effort (1993, Chapter 5).

A more directly relevant set of experiences with respect to inflations at more moderate levels have been the Nordic countries. This is because, in these countries, incomes policies have been used successfully as a tool for maintaining relatively low inflation over long periods of time rather than as primarily an instrument of disinflation after inflation exceeded 40 percent, as was true with Mexico and Israel. Sweden, for example, succeeded in maintaining unemployment at an average rate below 2 percent between 1951 - 2000 while still holding inflation at a 4.4 percent average rate. The application of incomes policies in Sweden, moreover, primarily took the form of centralized bargaining between unions and business, through which the aim of inflation control was recognized in the bargaining process. As such, the government did not have to rely on setting mandates for acceptable wage and price increases. The government did

\footnotetext{
${ }^{5}$ Even some of the most recent work by IMF economists has recognized that, at least for the low-income countries, inflation in the range of $5-10$ percent is likely to be supportive of economic growth. See IMF (2005).
} 
also utilize fiscal and monetary policies as tools for controlling inflation. But they did not have to apply these tools stringently, precisely because they were able to rely on their well-developed system of incomes policies as a complement to monetary and fiscal policies. $^{6}$

The most basic critique of incomes policies is that, in order for the approach to have any chance of success, it is necessary that a country operate with a high level of organization among workers, and that there be some reasonable degree of common ground between workers and business. Otherwise, there will be no realistic prospect for economy-wide bargaining to yield results that will be honored widely. By its very nature, the relationship between unions and business in capitalist economies is likely to be highly contentious. But this could possibly diminish to the extent that both sides see the benefits accelerated economic growth and employment expansion as opposed to maintaining tight monetary policy for the purpose of holding inflation within a $3-5$ percent band.

This point brings us to a final issue for further research that includes both purely analytic as well as policy-oriented implications. This is to examine the relationship between inflation and inequality in addition to the inflation/growth relationship. To the extent that inflation is associated with faster economic growth, it is likely to also be correlated with faster employment growth and thereby increased equality. At the same time, to the extent that wage agreements and social benefits do not include adequate costof-living adjustments, even a growth-generated inflation could yield greater inequality. In terms of policy implications, the issues that are central in the exploration of the inflation-inequality relationship will also be closely linked to the question of inflation control policies. For example, are incomes policies or inflation targeting a more effective means of promoting greater equality as well as economic growth? These are crucial questions that deserve substantial additional research in an effort to design more effective analytic foundations for the conduct of macroeconomic policy.

\footnotetext{
${ }^{6}$ Different perspectives on the Nordic experiences are presented in Calmfors (1993), Pekkarinen, Pohjola, and Rowthorn (1992), Flanigan (1999), Marshall (1994), and Iversen, Pontusson and Soskice (2000).
} 


\section{APPENDIX}

Countries Included In Data Pool For Analyzing The Inflation/Economic Growth Relationship

Data Sample is 1960 - 2001

\begin{tabular}{lllll}
\hline OECD Countries & Middle Income Countries & Non-OECD & Low \\
& & & $\begin{array}{l}\text { Income } \\
\text { Highcome } \\
\text { Countries }\end{array}$ & Countries \\
\hline Australia & Algeria & Paraguay & Israel & Bangladesh \\
Austria & Argentina & Peru & Singapore & Burundi \\
Belgium & Bolivia & Philippines & & Cameroon \\
Canada & Brazil & Poland & & Central Afr. R. \\
Denmark & Chile & South & & Congo \\
Finland & China & Africa & & Ghana \\
France & Colombia & Sri Lanka & & Haiti \\
Greece & Costa Rica & Thailand & & India \\
Ireland & Dominican Rep. & Tunisia & & Indonesia \\
Italy & Ecuador & Uruguay & & Kenya \\
Japan & Egypt & Venezuela & & Lesotho \\
Korea & El Salvador & & Malawi \\
Netherlands & Guatemala & & Mali \\
New Zealand & Honduras & & Nepal \\
Norway & Hungary & & Nicaragua \\
Portugal & Iran, I.R. of & & Niger \\
Spain & Jamaica & & Pakistan \\
Sweden & Jordan & & Papua New Guin. \\
Switzerland & Malaysia & & Rwanda \\
United Kingdom & Mexico & & Senegal \\
United States & Panama & & Sierra Leone \\
& & & Togo \\
& & & Uganda \\
& & & Zaire \\
& & & Zimbabwe \\
\hline
\end{tabular}




\section{Specifications of Variables In The Full Inflation/Economic Growth Model}

Economic Growth. Real GDP per capita (Constant price: Laspeyres) Growth rate. The nth year's growth rate is calculated as the log value of the ratio of the nth year's per capita GDP to the (n1)th year’s per capita GDP. (Source: PWT6.1. http://pwt.econ.upenn.edu/. )

Inflation. The increase of consumer price index. (Source: WDI2003)

Initial Output Level. The log value of per capita GDP (Constant price: Laspeyres) at the beginning year of each period. (Source: PWT6.1. http://pwt.econ.upenn.edu/.)

Investment. The share of gross investment in GDP (current prices). (Source: PWT6.1. http://pwt.econ.upenn.edu/. ).

Fiscal Policy. 1) The share of government consumption in GDP (current prices). (Source: PWT6.1. http://pwt.econ.upenn.edu/). 2) Government budget deficit as percentage of GDP, (Source: WDI 2003)

Life Expectancy. Life expectancy at birth. (Source: WDI CD-ROM 2003, World Bank.)

Education Level. Average years of secondary schooling in the of the total population aged 25 and over. (Source: Barro R. and J.W. Lee, 2000.http://www2.cid.harvard.edu/ciddata/barrolee/panel_data.xls)

Terms of Trade. . The change of terms of trade weighted by foreign trade dependence ratio (the sum of exports and imports divided by GDP). (Easterly, et al. 2002. Global Development Network Growth Database, http://www.worldbank.org/research/growth/GDNdata.htm.)

Natural Disaster. The share of population affected by the natural disasters happened in the year weighted by the share of agricultural output in GDP. Unreported natural disasters, if any, are treated as 0. (Sources: The natural disaster data come from The Centre for Research on the Epidemiology of Disasters (CRED), The OFDA/CRED International Disaster Database. http://www.cred.be/emdat/intro.htm. The agricultural data are from WDI 2003.)

War. A war is defined as an armed conflict with more than 25 deaths. Value 1 is given to those countries experienced war within its border, -1 given to those countries involved into war in other countries. Other situations are given value 0. (Source: Gleditsch, et al., 2002, Armed Conflict 1946-2002 database. http://www.prio.no/cwp/ArmedConflict/)

Note: All variables are averaged over 5-year period in the full period regressions presented in Table 2. Annual data are used in the decade-by-decade regressions presented in Table 3. 


\section{References}

Bernanke, Ben S., Thomas Laubach, Adam S. Posen and Frederic S. Mishkin (1999) Inflation Targeting: Lessons from the International Experience. Princeton, NJ: Princeton University Press.

Blinder, Alan S. (1998) Central Banking in Theory and Practice. Cambridge, MA: MIT Press.

Bruno, Michael (1993) Crisis, Stabilization, and Economic Reform: Therapy by Consensus, Oxford: Clarendon Press.

Bruno, Michael (1995) “Does Inflation Really Lower Growth?” Finance and Development, September, pp. $35-38$.

Bruno, Michael and Easterly, William (1998) "Inflation Crises and Long-Run Growth,” Journal of Monetary Economics, 41, pp. 3 - 26.

Burdekin, Richard C.K., Denzau, Arthur T., Keil, Manfred W., Sitthiyot, Thitithep, and Willett, Thomas D. (2004) "When Does Inflation Hurt Economic Growth? Different Nonlinearities for Different Economies,” Journal of Macroeconomics, 26, pp. 519 - 32.

Calmfors, Lars (1993) “Centralization of Wage Bargaining and Macroeconomic Performance,” OECD Economic Studies, No. 21, Winter, pp. 161-91.

Cross, Rod ed. (1995) The Natural Rate of Unemployment: Reflections on 25 Years of the Hypothesis, Cambridge, UK: Cambridge University Press.

Dornbusch, Rudiger and Fischer, Stanley (1991) “Moderate Inflation,” National Bureau of Economic Research Working Paper \#3896.

Robert J. Flanigan, “Macroeconomic Performance and Collective Bargaining: An International Perspective,” Journal of Economic Literature, September 1999, 1150-1175.

Ghosh, Atish and Phillips, Steven (1998) "Warning: Inflation May Be Harmful to Your Growth," IMF Staff Papers, 45 (4), pp. 672-86.

International Monetary Fund. 2005. "Monetary and Fiscal Policy Design Issues in Low-Income Countries”. August 8 draft. Policy Development and Review Department and Fiscals Affairs Department, Washington DC: IMF.

Iversen, T., Jonas Pontusson, Jonas, and Soskice, David, eds., (2000) Unions, Employers, and Central Banks, Cambridge 2000.

Khan, Mohsin S. and Senhadji, Abdelhak S. (2001) "Threshold Effects in the Relationship Between Inflation and Growth,” IMF Staff Papers, 48:1, 1 - 21.

Alan Krueger and Robert M. Solow eds (2001) The Roaring Nineties: Can Full Employment Be Sustained? New York: The Russell Sage Foundation and the Century Foundation.

Maddison, Angus (2001) The World Economy: A Millennial Perspective, Paris: Development Centre of the Organization for Economic Cooperation and Development.

Marshall, Mike (1994) “Lessons from the Experience of the Swedish Model,” in P. Arestis and M. Marshall eds., The Political Economy of Full Employment, Ch. 10.

Pekkarinen, P., Pohjola, M. and Rowthorn, B. (1992) Social Corporatism: A Superior Economic System? New York : Oxford University Press. 
Saad Filho, Alfredo (2005) "Pro-poor Monetary and Anti-Inflation Policies: Developing Alternatives to the New Monetary Policy Consensus”, manuscript, Department of Development Studies, SOAS, University of London. 
Table 1. Descriptive Statistics on GDP Growth and Inflation

80-Country Sample, 1961 - 2000

(figures are percentages)

\begin{tabular}{|l|r|r|r|r|}
\hline & $\begin{array}{l}\text { All countries } \\
\mathbf{8 0} \text { countries) }\end{array}$ & $\begin{array}{l}\text { OECD } \\
\text { countries } \\
\text { (21 countries) }\end{array}$ & $\begin{array}{l}\text { Middle-income } \\
\text { countries } \\
\text { (32 countries) }\end{array}$ & $\begin{array}{l}\text { Low-income } \\
\text { Countries } \\
\text { (25 countries) }\end{array}$ \\
\hline GDP growth & 1.9 & & & \\
\hline Mean & 2.7 & 1.8 & 2.8 & 3.4 \\
\hline $\begin{array}{l}\text { Standard } \\
\text { deviation }\end{array}$ & & & & \\
\hline Inflation & 10.2 & & & \\
\hline Mean & 7.2 & 7.0 & 12.8 & 11.3 \\
\hline $\begin{array}{c}\text { Standard } \\
\text { deviation }\end{array}$ & & 4.9 & 8.3 & 6.6 \\
\hline
\end{tabular}

Source: See Appendix.

Note: Israel and Singapore are not included in the country-groupings because they are non-OECD highincome countries. 
TABLE 2

Inflation and Economic Growth, 1961 -2000

Data grouped as five-year averages

Dependent Variable is GDP Growth

(t-statistics in parentheses; $\mathrm{P}<0.05=*, \mathrm{P}<0.01=* *$ )

\begin{tabular}{|c|c|c|c|c|c|c|c|c|}
\hline \multirow[b]{2}{*}{ Model : } & \multicolumn{4}{|c|}{ All Countries } & \multicolumn{4}{|c|}{ OECD Countries } \\
\hline & Pooled-OLS & $\begin{array}{l}\text { Fixed } \\
\text { Effects }\end{array}$ & $\begin{array}{c}\text { Random } \\
\text { Effects }\end{array}$ & $\begin{array}{c}\text { Between } \\
\text { Effects }\end{array}$ & Pooled-OLS & $\begin{array}{l}\text { Fixed } \\
\text { Effects }\end{array}$ & $\begin{array}{c}\text { Random } \\
\text { Effects }\end{array}$ & $\begin{array}{c}\text { Between } \\
\text { Effects }\end{array}$ \\
\hline \# obs : & 356 & 356 & 356 & 80 & 135 & 135 & 135 & 21 \\
\hline \multirow[t]{2}{*}{ Inflation } & $0.11^{*}$ & 0.091 & $0.11^{*}$ & $0.149 *$ & -0.055 & 0.025 & -0.034 & -0.130 \\
\hline & (2.49) & $(1.61)$ & $(2.55)$ & $(1.99)$ & $(-0.66)$ & $(0.23)$ & $(-0.36)$ & $(-0.30)$ \\
\hline \multirow[t]{2}{*}{ (Inflation) $^{2}$} & $-0.003 * *$ & $-0.003^{*}$ & $-0.003 * *$ & $-0.004 *$ & -0.005 & -0.007 & -0.005 & 0.001 \\
\hline & $(-3.73)$ & $(-2.41)$ & $(-3.42)$ & $(-2.35)$ & $(-1.43)$ & $(-1.79)$ & $(-1.37)$ & $(0.06)$ \\
\hline \multirow[t]{2}{*}{$\begin{array}{l}\text { Turning } \\
\text { Point }\end{array}$} & 18.3 & 15.2 & 18.3 & 18.6 & -5.5 & 1.8 & -3.4 & 65.0 \\
\hline & \multicolumn{4}{|c|}{ Middle-Income Countries } & \multicolumn{4}{|c|}{ Low-Income Countries } \\
\hline Model : & Pooled-OLS & $\begin{array}{l}\text { Fixed } \\
\text { Effects }\end{array}$ & $\begin{array}{c}\text { Random } \\
\text { Effects }\end{array}$ & $\begin{array}{c}\text { Between } \\
\text { Effects }\end{array}$ & $\begin{array}{l}\text { Pooled- } \\
\text { OLS }\end{array}$ & $\begin{array}{l}\text { ixed } \\
\text { ffects }\end{array}$ & $\begin{array}{l}\text { Random } \\
\text { Effects }\end{array}$ & $\begin{array}{c}\text { Between } \\
\text { Effects }\end{array}$ \\
\hline \# obs : & 127 & 127 & 127 & 32 & 86 & 86 & 86 & 25 \\
\hline \multirow[t]{2}{*}{ Inflation } & 0.06 & 0.028 & 0.057 & 0.129 & 0.359 & $0.559 *$ & $0.386^{*}$ & 0.238 \\
\hline & (1.12) & $(0.31)$ & $(0.84)$ & (1.19) & (1.38) & (2.38) & (2.29) & $(0.73)$ \\
\hline \multirow[t]{2}{*}{ (Inflation) $^{2}$} & $-0.002 *$ & -0.001 & -0.002 & -0.004 & -0.01 & $-0.012 *$ & $-0.01 *$ & -0.008 \\
\hline & $(-2.45)$ & $(-0.84)$ & $(-1.67)$ & $(-1.71)$ & (1.55) & $(2.20)$ & (2.36) & $(0.72)$ \\
\hline $\begin{array}{l}\text { Turning } \\
\text { Point }\end{array}$ & 15.0 & 14.0 & 14.3 & 16.1 & 18.0 & 23.3 & 19.3 & 14.9 \\
\hline
\end{tabular}

Note: All countries with less than 2 million people were excluded from the sample. All observations with inflation above 40 percent were excluded. Five-year period average data were used instead of yearly data in the regression. "Non-low Income Countries" include OECD countries, middle income countries and non-OECD high income countries. "All countries" refers to all the countries in this table. 
TABLE 3

Inflation and Economic Growth

All Countries by Decades

Annual data

Dependent Variable is GDP Growth

(t-statistics in parentheses; $\mathrm{P}<0.05=*, \mathrm{P}<0.01=* *$ )

\begin{tabular}{|c|c|c|c|c|c|c|c|c|}
\hline \multirow{2}{*}{$\begin{array}{l}\text { Years } \\
\text { Model : }\end{array}$} & \multicolumn{4}{|c|}{$1961-70$} & \multicolumn{4}{|c|}{$1971-80$} \\
\hline & Pooled OLS & $\begin{array}{c}\text { Fixed } \\
\text { Effects }\end{array}$ & $\begin{array}{c}\text { Random } \\
\text { Effects }\end{array}$ & $\begin{array}{c}\text { Between } \\
\text { Effects }\end{array}$ & Pooled-OLS & $\begin{array}{c}\text { Fixed } \\
\text { Effects }\end{array}$ & $\begin{array}{c}\text { Random } \\
\text { S Effects }\end{array}$ & $\begin{array}{c}\text { Between } \\
\text { Effects }\end{array}$ \\
\hline \# obs: & 480 & 480 & 480 & 59 & 620 & 620 & 620 & 71 \\
\hline \multirow[t]{2}{*}{ Inflation } & 0.112 & 0.065 & 0.109 & $0.61 *$ & 0.084 & 0.06 & 0.084 & 0.047 \\
\hline & (1.04) & $(.070)$ & (1.24) & (2.08) & $(0.99)$ & $(0.61)$ & $(0.92)$ & $(0.20)$ \\
\hline \multirow{2}{*}{ (Inflation) $^{2}$} & -.0005 & $-0.007 *$ & -0.006 & $-0.024 *$ & $-0.005^{*}$ & $-0.006 *$ & $-0.005 *$ & 0.001 \\
\hline & (1.47) & (2.10) & (1.74) & (2.08) & (2.00) & (2.21) & (2.03) & $(0.13)$ \\
\hline $\begin{array}{l}\text { Turning } \\
\text { Point }\end{array}$ & 11.2 & 4.6 & 9.1 & 12.7 & 8.4 & 5.0 & 8.4 & -23.5 \\
\hline Years & \multicolumn{4}{|c|}{1981 - 90} & \multicolumn{4}{|c|}{ 1991- 2000} \\
\hline Model : & $\begin{array}{l}\text { Pooled- } \\
\text { OLS }\end{array}$ & $\begin{array}{l}\text { Fixed } \\
\text { Effects }\end{array}$ & $\begin{array}{l}\text { Random } \\
\text { Effects }\end{array}$ & $\begin{array}{c}\text { Between } \\
\text { Effects }\end{array}$ & $\begin{array}{l}\text { Pooled- } \\
\text { OLS }\end{array}$ & $\begin{array}{l}\text { ixed } \\
\text { ffects }\end{array}$ & $\begin{array}{c}\text { Random } \\
\text { Effects }\end{array}$ & $\begin{array}{c}\text { Between } \\
\text { Effects }\end{array}$ \\
\hline \# obs: & 718 & 718 & 718 & 85 & 698 & 698 & 698 & 106 \\
\hline \multirow[t]{2}{*}{ Inflation } & -0.016 & $-0.118^{*}$ & -0.016 & -0.016 & 0.025 & -0.13 & 0.01 & -0.189 \\
\hline & $(0.31)$ & (1.98) & $(0.33)$ & $(0.17)$ & $(0.31)$ & (1.69) & $(0.15)$ & (1.32) \\
\hline \multirow{2}{*}{ (Inflation) $^{2}$} & 0.00 & 0.001 & 0.00 & 0.003 & -0.003 & -0.001 & -0.003 & 0.004 \\
\hline & $(0.008)$ & $(0.61)$ & $(0.08)$ & $(0.91)$ & $(1.30)$ & $(0.43)$ & $(1.70)$ & $(0.87)$ \\
\hline $\begin{array}{l}\text { Turning } \\
\text { Point }\end{array}$ & - & 59.0 & - & 2.7 & 4.2 & -65.0 & 1.7 & 23.6 \\
\hline
\end{tabular}

Note: All countries with less than 2 million people were excluded from the sample. All observations with inflation above 40 percent were excluded. Five-year period average data were used instead of yearly data in the regression. "Non-low Income Countries" include OECD countries, middle income countries and non-OECD high income countries. "All countries” refers to all the countries in this table. 
Figure 1. Inflation and Economic Growth, 1961 - 2000

\section{Annual data are grouped into 5-year averages}
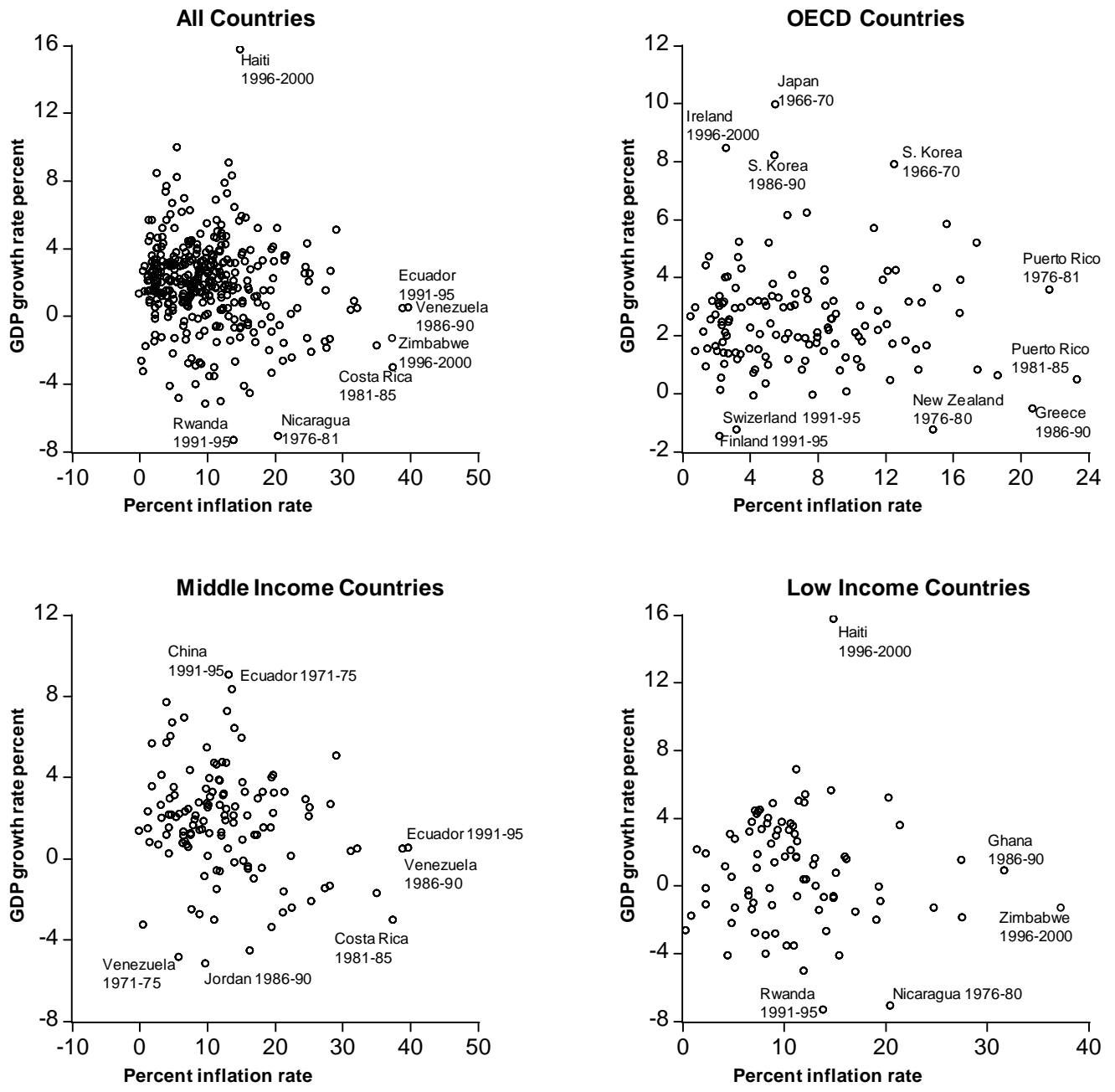

Source: See Appendix 